\title{
Maternal obesity and its association with the mode of delivery and the neonatal outcome in induced labour: Implications for midwifery practice
}

\author{
Antonakou Angeliki ${ }^{1}$, Papoutsis Dimitrios ${ }^{2}$, Tzavara Chara ${ }^{3}$
}

\begin{abstract}
INTRODUCTION Maternal obesity carries an increased risk of complications during pregnancy and childbirth. This study investigated whether the body mass index (BMI) of women with induced labour was associated with the mode of delivery and neonatal outcome.

METHODS This was a retrospective study of primigravidae women under the age of 40 years who were induced at term for various indications. Data were collected from the electronic database of the Maternity Unit where these women gave birth.

RESULTS We sampled 1274 women with a mean age of $26.3 \pm 5.9$ years. The mean BMl at booking was $26.5 \mathrm{~kg} / \mathrm{m}^{2}$, with $28.8 \%$ being overweight and $24.3 \%$ obese. In the sample, $70.4 \%$ had a normal vaginal delivery, $15.4 \%$ a caesarean section (CS) and $14.2 \%$ an instrumental delivery. An increasing BMI was independently associated with the odds for a CS, with women who were overweight and obese having a 1.58 and 2.75 times greater likelihood for a CS. The CS rate was $10.2 \%$ in women with a normal BMI, and increased to $15.8 \%$ for overweight and $24.9 \%$ for obese women $(p<0.001$ ). The increasing BMI did not affect the instrumental delivery rates in our cohort. The Apgar scores at one and five minutes were significantly lower in overweight and obese women compared to women with a normal BMI.

CONCLUSIONS We show that an increasing BMI in women with induced labour was associated with increased CS rates and lower Apgar scores. These findings highlight the important role of midwives in engaging women in weight management before they get pregnant.
\end{abstract}

\author{
AFFILIATION \\ 1 Department of Midwifery, \\ Midwifery School, 'Alexander' \\ Technological Educational \\ Institute of Thessaloniki, Greece \\ 2 Department of Obstetrics \\ and Gynaecology, Shrewsbury \\ and Telford Hospital NHS Trust, \\ Shrewsbury, United Kingdom \\ 3 Department of Hygiene, \\ Epidemiology and Medical \\ Statistics, Medical School, \\ University of Athens, Greece
}

\section{CORRESPONDENGE TO}

Angeliki Antonakou. Department of Midwifery, Midwifery School, 'Alexander' Technological Educational Institute of Thessaloniki, PC 57400, Greece. E-mail: angelantonakou@gmail. com

\section{KEYWORDS \\ induction of labour, caesarean section, body mass index, primigravidae \\ Received: 28 October 2017 \\ Revised: 27 January 2018 \\ Accepted: 26 February 2018}

\section{INTRODUGTION}

According to the World Health Organization, women can be classified into four groups according to body mass index (BMI): underweight $\left(<18.5 \mathrm{~kg} / \mathrm{m}^{2}\right)$, normal $(18.5-24.9 \mathrm{~kg} /$ $\left.\mathrm{m}^{2}\right)$, overweight $\left(25.0-29.9 \mathrm{~kg} / \mathrm{m}^{2}\right)$ and obese ( $\geq 30.0 \mathrm{~kg} /$ $\left.\mathrm{m}^{2}\right)^{1}$. There are reports that more and more women are overweight at the start of their pregnancy (BMI at booking $\geq 25 \mathrm{~kg} / \mathrm{m}^{2}$ ) with rates ranging between $15 \%$ to $30 \%^{2,3}$. In England about half of women who are of childbearing age are either overweight or obese, with more than $15 \%$ being obese at the start of their pregnancy $y^{4,5}$.
Pregnant women who are obese at booking have an increased risk for complications, both for themselves and their babies during pregnancy and childbirth ${ }^{6}$. Women who are obese are at risk for gestational diabetes, miscarriage, preeclampsia, thromboembolism and postpartum hemorrhage ${ }^{7,8}$. There is a growing body of evidence that maternal obesity might represent an independent risk factor for an instrumental delivery ${ }^{8,9}$ and caesarean-section delivery ${ }^{10}$, and for adverse neonatal outcomes ${ }^{11,12}$ such as macrosomia, shoulder dystocia and stillbirth. The birthing choices of obese women may also be limited from restrictions in the use of birthing 
pools, on home births and the type of pain relief that can be given ${ }^{6}$. Moreover, after birth obese women are more likely to require additional support in breastfeeding due to difficulties in latching the baby on the breast ${ }^{13}$.

Women are more likely to have an induced labour due to associated complications of obesity during pregnancy ${ }^{8}$. In the United Kingdom, during 2011-2012, the rate of induction of labour in the general obstetric population was 22.1\%, while during 2013-2014 it had risen to $25 \%^{14}$. Moreover, there are literature reports that the rates of induced labour are increasing worldwide ${ }^{15}$. It is thought that induced labour is less efficient than a spontaneous onset labour and therefore women who are induced are twice as likely to have a caesarean-section delivery ${ }^{16}$ or an assisted delivery ${ }^{17}$.

The aim of our study was to investigate the effect of the maternal BMI at booking with the mode of delivery and the neonatal outcome in women with induced labour. In order to account for the significant confounding factors of parity ${ }^{3}$, maternal age ${ }^{18}$, use of an epidural in labour ${ }^{19}$ and ethnicity ${ }^{20}$ on the success of induced labour, we restricted the inclusion criteria of our women to those who were primigravidae, under 40 years, of white-European ethnic background, and who did not use an epidural for analgesia during labour. We compare our findings against the evidence from existing literature, and highlight the significant role of midwives in the weight management of women before and during pregnancy.

\section{METHODS}

This was a retrospective cohort study of women who were induced for various indications at term (gestational age $\geq 37$ weeks) at the Maternity Unit, of the Shrewsbury and Telford Hospital NHS Trust, between January 2007 and December 2013.. The inclusion criteria that were applied included primigravidae-only women with singleton cephalic presentation deliveries, who were under 40 years old, without the use of epidural analgesia during labour and who self-reported that they were of white-European ethnic background. We selected these inclusion criteria because there is evidence that parity, increased maternal age, use of an epidural and non-white-European ethnic background are all risk factors that have a confounding effect on the outcome of induced labour $3,18-20$. Women who were induced for stillbirths, fetal congenital abnormalities and multiple pregnancies were excluded from the analysis. Data were collected from the obstetric electronic database of the Maternity Unit, and maternal features, labour and delivery characteristics, and neonatal data, were recorded.

The indications for the induction of labour were: post-dates pregnancy (gestational age at more than 41 weeks), reduced fetal movements, fetal growth restriction, hypertensive disorders of pregnancy (preeclampsia/eclampsia), diabetes mellitus (gestational or preexisting), and term pre-labour rupture of membranes for more than 24 hours. Other indications included intrahepatic cholestasis of pregnancy, maternal age over 40 years, and maternal request for social or mental health issues.

We included only women who had complete data for their body mass index (BMI) at booking. Other maternal features recorded were maternal age at delivery and their smoking status. Labour and delivery data included gestational age at birth, route of birth (normal vaginal delivery, instrumental vaginal delivery, caesarean section delivery) and liquor appearance (normal, meconium stained). The neonatal data that were recorded involved fetal gender (male, female), birth weight, head circumference, Apgar scores (at 1 and 5 minutes), cord gases taken at delivery (arterial/venous $\mathrm{pH}$ ), and any possible admission to the neonatal unit.

Ethical approval for the collection and analysis of data in our study was obtained by the Research and Development Department of the Shrewsbury and Telford Hospital NHS Trust.

\section{Statistical analysis}

Quantitative variables were expressed as mean values (and standard deviations) or as median values (and interquartile range), while qualitative variables were expressed as absolute and relative frequencies. For the comparison of proportions chi-squared tests were used, and the Mann-Whitney test was computed for the comparison of median values between two groups when the distribution was not normal. Univariate and multiple logistic regression analyses were used to find factors associated with the likelihood of having a caesarean section. Odds ratios (OR) with 95\% confidence intervals $(95 \% \mathrm{Cl})$ were computed from the results of the logistic regression analysis. All reported $p$ values were two-tailed. Statistical significance was set at $p<0.05$ and analyses were conducted using SPSS statistical software (version 19.0).

\section{RESULTS}

Our sample consisted of 1274 women who had induced labour and a mean age of 26.3 years $(S D=5.9)$. The mean $\mathrm{BMI}$ was $26.5 \mathrm{~kg} / \mathrm{m}^{2}$ (SD=5.9), with $28.8 \%$ of the women being overweight and $24.3 \%$ obese. The percentage of women having a normal vaginal delivery was $70.4 \%$, while $15.4 \%$ had a caesarean section and $14.2 \%$ an instrumental delivery (4.5\% forceps, $8.9 \%$ ventouse, and $0.9 \%$ a dual instrumental delivery with forceps and ventouse). The indication for the CS delivery was recorded on the electronic database in $75 \%$ of the women in our sample, with failed induction of labour, failure to progress in labour, cardiotocographic abnormalities, and other indications such as maternal pyrexia, chorioamnionitis and placental abruption being 18\%, 35\%, 29.9\% and $17.1 \%$, respectively. There was meconium stained liquor in 15\% of all deliveries and $4.5 \%$ of the newborns were admitted to the Neonatal Unit (Table 1).

The proportion of women that had a normal vaginal delivery, caesarean section or instrumental delivery according to their BMI status is shown in Figure 1. There was a significantly increasing trend in the proportion of women who had a caesarean-section delivery with increasing BMI. The percentage of women who had caesarean section was $10.2 \%$ for a normal BMI, $15.8 \%$ for the overweight, and $24.9 \%$ for the obese $(p<0.001)$. The percentage with instrumental delivery was $16.2 \%$ for a normal BMI, $13.6 \%$ for the overweight, and $11 \%$ for the obese, and was nonsignificantly different $(p=0.481)$.

Table 2 presents the results from the univariate and 
Figure 1. Proportion of women that had a normal vaginal delivery, caesarean section or instrumental delivery according to the BMI status

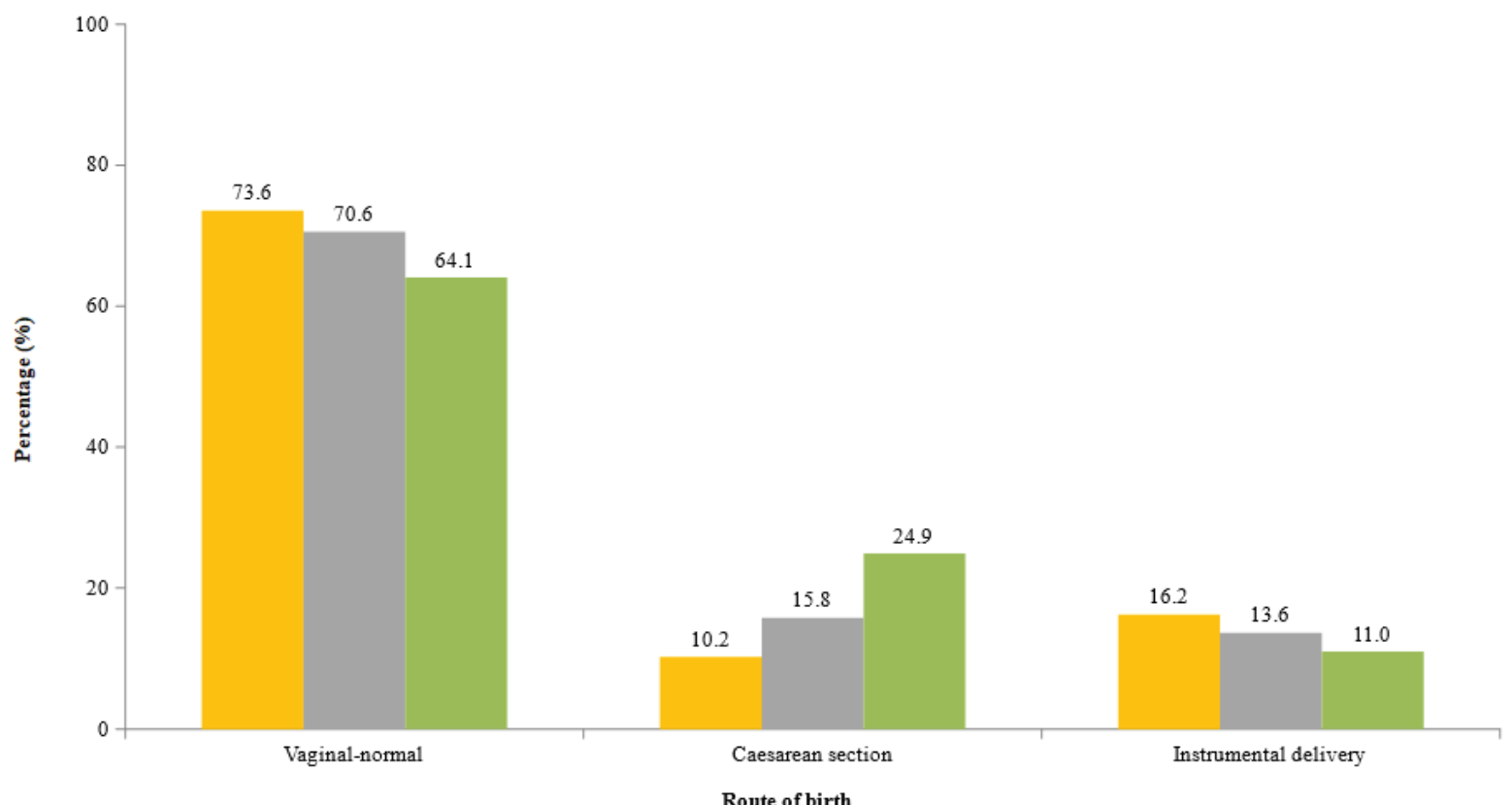

Normal Overweight Obese

Table 1. The demographic features of women and the labour, delivery and neonatal characteristics

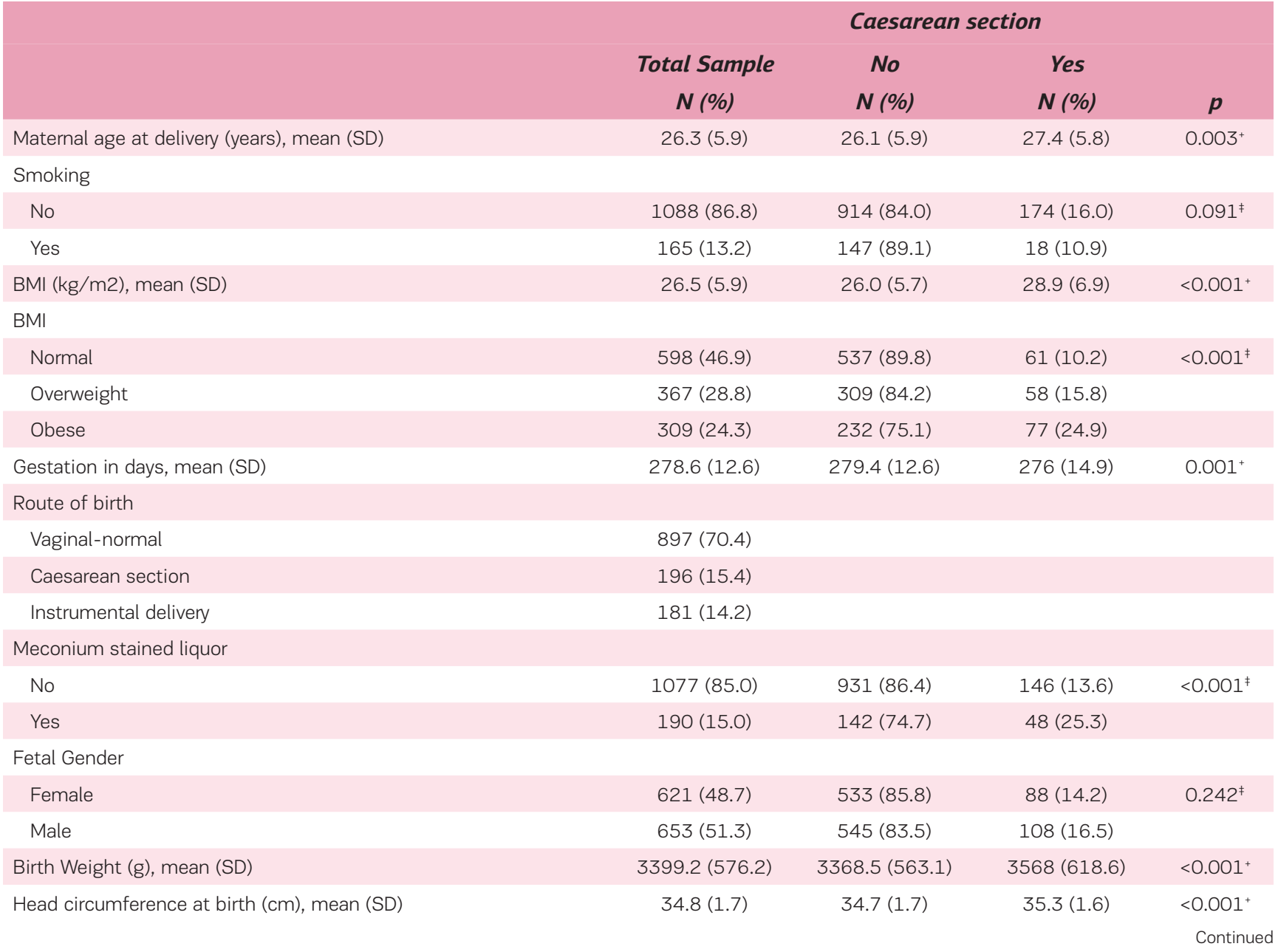


Table 1. Continued

\begin{tabular}{|c|c|c|c|c|}
\hline & \multicolumn{4}{|c|}{ Caesarean section } \\
\hline & Total Sample & No & Yes & \\
\hline & $N(\%)$ & $N(\%)$ & $N(\%)$ & $p$ \\
\hline Apgar score at 1 minute, median (IQR) & $9(8-9)$ & $9(9-9)$ & $9(8-9)$ & $<0.001^{++}$ \\
\hline Apgar score at 5 minutes, median (IQR) & $10(10-10)$ & $10(10-10)$ & $10(9-10)$ & $<0.001^{++}$ \\
\hline Cord gases taken at delivery Arterial pH, median (IQR) & $7.24(7.18-7.29)$ & $7.22(7.17-7.28)$ & $7.25(7.20-7.29)$ & $0.001^{++}$ \\
\hline Cord gases taken at delivery Venus pH, median (IQR) & $7.29(7.24-7.33)$ & $7.29(7.25-7.33)$ & $7.29(7.23-7.33)$ & $0.365^{++}$ \\
\hline \multicolumn{5}{|l|}{ Admitted to the Neonatal Unit (NNU) } \\
\hline No & 1005 (95.5) & $853(84.9)$ & $152(15.1)$ & $<0.001^{\ddagger}$ \\
\hline Yes & $47(4.5)$ & $29(61.7)$ & $18(38.3)$ & \\
\hline
\end{tabular}

+Student t-test; ++Mann-Whitney test; $¥$ Pearson chi-squared test

Table 2. Results from the univariate and multiple analyses with dependent variable the caesarean section

\begin{tabular}{|c|c|c|c|c|}
\hline & \multicolumn{2}{|c|}{ Univariate analysis } & \multicolumn{2}{|c|}{ Multiple analysis } \\
\hline & OR $(95 \% \mathrm{CI})+$ & $p$ & OR $(95 \% \mathrm{CI})+$ & $p$ \\
\hline Maternal age at delivery (years), mean (SD) & $1.04(1.01-1.07)$ & 0.003 & $1.03(0.99-1.06)$ & 0.058 \\
\hline \multicolumn{5}{|l|}{ Smoking } \\
\hline No & $1.00^{++}$ & & $1.00^{++}$ & \\
\hline Yes & $0.64(0.38-1.08)$ & 0.093 & $0.88(0.51-1.53)$ & 0.650 \\
\hline Gestation in days, mean (SD) & $0.98(0.9-0.99)$ & 0.001 & $0.99(0.98-1.01)$ & 0.357 \\
\hline \multicolumn{5}{|l|}{ Meconium stained liquor } \\
\hline No & 1.00 & & 1.00 & \\
\hline Yes & $2.16(1.49-3.12)$ & $<0.001$ & $1.60(1.07-2.40)$ & 0.023 \\
\hline \multicolumn{5}{|l|}{ Fetal Gender } \\
\hline Female & 1.00 & & 1.00 & \\
\hline Male & $1.20(0.88-1.63)$ & 0.242 & $1.12(0.80-1.57)$ & 0.506 \\
\hline Birth Weight (g), mean (SD) & $1.07(1.04-1.10)$ & $<0.001$ & $1.01(0.97-1.06)$ & 0.545 \\
\hline Head circumference at birth (cm), mean (SD) & $1.27(1.15-1.40)$ & $<0.001$ & $1.21(1.05-1.39)$ & 0.010 \\
\hline \multicolumn{5}{|l|}{$\mathrm{BMI}\left(\mathrm{kg} / \mathrm{m}^{2}\right)$} \\
\hline Normal & 1.00 & & 1.00 & \\
\hline Overweight & 1.65 (1.12-2.43) & 0.011 & $1.58(1.06-2.34)$ & 0.024 \\
\hline Obese & $2.92(2.02-4.23)$ & $<0.001$ & $2.75(1.87-4.03)$ & $<0.001$ \\
\hline
\end{tabular}

+Odds Ratio (95\% Confidence Interval); ++indicates reference category; I per $100 \mathrm{~g}$

multiple analyses with dependent variable the caesareansection rate. The univariate analysis showed that increased maternal age, gestational age, presence of meconium stained liquor, increased birth weight, increased head circumference and maternal BMI were associated with a greater risk for a caesarean section. Multiple logistic regression analysis showed that the presence of meconium-stained liquor, increased head circumference and increased maternal BMI were independently associated with the odds for a caesarean section. It was estimated that women with the presence of meconium-stained liquor had a 1.60 times greater likelihood for a caesarean section. Moreover, women who were overweight and obese had a 1.58 and 2.75 times greater likelihood for having a caesarean section, respectively.

Table 3 shows the neonatal outcomes according to the BMI status of the mother. The $\mathrm{pH}$ values of the arterial and venous cord blood samples were not significantly different between women with a normal BMl and those who were overweight or obese. The proportion of neonates that were admitted to the Neonatal Unit was no different between women with a normal $\mathrm{BMI}$ and those who were overweight or obese. However, the Apgar scores at 1 and 5 minutes were significantly lower for babies born to women who were overweight or obese compared to those born to women who had a normal BMl $(p<0.001)$. When the analysis was repeated for normal deliveries only, no significant differences were found. 
Table 3. Neonatal outcomes according to the BMI status of the mother

\begin{tabular}{|c|c|c|c|c|c|}
\hline \multirow[b]{3}{*}{ Total sample } & \multicolumn{5}{|c|}{$B M I$} \\
\hline & \multicolumn{2}{|c|}{ Normal } & \multicolumn{3}{|c|}{ Overweight/Obese } \\
\hline & Mean (SD) & Median (IQR) & Mean (SD) & Median (IQR) & $p$ \\
\hline Apgar score at 1 minute & $8.5(1.3)$ & $9(-9)$ & $8.4(1.5)$ & $9(8-9)$ & $<0.001^{+}$ \\
\hline Apgar score at 5 minutes & $9.7(0.8)$ & $10(10-10)$ & $9.6(0.8)$ & $10(9-10)$ & $<0.001^{+}$ \\
\hline Cord gases taken at delivery Arterial pH & $7.23(0.08)$ & $7.23(7.18-7.29)$ & 7.22 (0.09) & $7.24(7.18-7.28)$ & $0.201^{+}$ \\
\hline Cord gases taken at delivery Venous $\mathrm{pH}$ & $7.28(0.07)$ & $7.29(7.24-7.33)$ & $7.28(0.07)$ & $7.29(7.24-7.33)$ & $0.365^{+}$ \\
\hline \multicolumn{6}{|l|}{ Admitted to the Neonatal Unit, N (\%) } \\
\hline No & $472(96.1)$ & & $533(95.0)$ & & $0.380^{++}$ \\
\hline Yes & $19(3.9)$ & & $28(5.0)$ & & \\
\hline \multicolumn{6}{|l|}{ Normal deliveries } \\
\hline Apgar score at 1 minute & $8.7(1.0)$ & $9(9-9)$ & $8.6(1.1)$ & $9(-9)$ & $0.069^{+}$ \\
\hline Apgar score at 5 minutes & $9.7(0.7)$ & $10(10-10)$ & $9.8(0.6)$ & $10(10-10)$ & $0.374^{+}$ \\
\hline Cord gases taken at delivery Arterial pH & $7.23(0.08)$ & $7.23(7.16-7.30)$ & $7.20(0.10)$ & $7.22(7.15-7.28)$ & $0.426^{+}$ \\
\hline Cord gases taken at delivery Venous $\mathrm{pH}$ & $7.29(0.05)$ & $7.29(7.25-7.32)$ & $7.29(0.07)$ & $7.30(7.25-7.33)$ & $0.411^{+}$ \\
\hline \multicolumn{6}{|l|}{ Admitted to the Neonatal Unit, N (\%) } \\
\hline No & $349(97.5)$ & & 369 (97.9) & & $0.724^{++}$ \\
\hline Yes & $9(2.5)$ & & $8(2.1)$ & & \\
\hline
\end{tabular}

+Mann-Whitney test; ++Pearson chi-squared test

\section{DISCUSSION}

This study found that the increasing maternal BMI recorded at booking was independently associated with the odds for a caesarean section, with overweight and obese women presenting a 1.58 and 2.75 times greater risk for a caesareansection delivery, respectively. This finding is in line with other studies that showed that the increasing maternal BMI was also associated with an increased emergency CS delivery rate, which was 1.30 and 1.83 times greater for overweight and obese women compared to normal BMI women ${ }^{11}$. The pathophysiological reason that has been postulated to be behind the increased caesarean-section delivery rates is that the increased BMI, due to the adipose tissue being hormonally active, may predispose women to a reduced response to induced labour because of altered metabolic status when overweight or obese ${ }^{21,22}$. Moreover, it is not impossible that some of the alleged effect on the increased CS delivery rates could be attributed to the more frequent deconditioning in women with a high $\mathrm{BMI}^{23}$. A recent meta-analysis has shown that structured physical exercise during pregnancy can reduce the risk of a CS by almost 15\%, probably through a significant reduction in overall weight gain in pregnancy ${ }^{24}$. Even though in our study we do not have any data on the physical activity of the women during pregnancy, we can hypothesize that being overweight and obese most probably reflects limited physical activity with subsequent increased weight gain in pregnancy and therefore a higher risk of CS.

In addition, other studies have reported that a high BMI is a risk factor for assisted delivery in both spontaneous and induced labour 9 . In contrast, our cohort study showed that the increasing BMI did not affect the instrumental delivery rates. We found differences in risk magnitude between caesareansection delivery in overweight/obese women and normal
BMI women, and that maternal BMI did not influence the instrumental delivery rates. These findings can be explained by the different study designs reported in the literature, which involved women that were both nulliparous and multiparous for both spontaneous onset and induced labours ${ }^{9,11}$.

This study has also shown that increased head circumference at birth was an independent risk factor that was associated with an increased risk of a caesarean section (adjusted odds ratio $=1.21$ ). There are studies reporting that increased head circumference may lead to cephalopelvic disproportion and therefore to a caesarean-section delivery ${ }^{25,26}$. Moreover, the presence of meconium-stained liquor was also associated with a caesarean-section delivery in our cohort (adjusted odds ratio=1.60). There is evidence that the presence of meconium in the amniotic fluid is a function of the duration of labour and may rise from $2.8 \%$ in women prior to the onset of labour in an elective caesarean section to $23.1 \%$ in women in active labour ${ }^{27}$. It has been suggested that the presence of meconium is a sign and indicator of fetal hypoxia, associated with lower Apgar scores and higher rates of assisted delivery ${ }^{27,28}$.

\section{Implications for midwifery practice}

In 2009 the Institute of Medicine (IOM) and the National Research Council (NRC) in the United States released a guideline on the recommended weight gain during pregnancy in relation to maternal pre-pregnancy BMI ${ }^{29}$. It was recommended that women with a normal BMI should gain no more than $35 \mathrm{lbs}$ (or $16 \mathrm{~kg}$ ) during pregnancy, overweight women should gain no more than $25 \mathrm{lbs}$ (or $11.5 \mathrm{~kg}$ ) and obese women no more than $20 \mathrm{lbs}$ (or $9 \mathrm{~kg}$ ). In the United Kingdom at present there are no formal, evidence-based guidelines from the UK Government or professional bodies on 
what constitutes appropriate weight gain during pregnancy ${ }^{6}$.

The IOM and NRC in September 2013 released an update reporting that many women still do not receive adequate preconception or post-conception advice about pregnancy-weight gain $^{30}$. A very recent study in the United Kingdom demonstrated that midwives, who are considered the frontline professionals in the provision of weight-related advice to pregnant women, are still biased when providing advice to obese women by their own personal beliefs about body image and so their counselling is not always evidence-based ${ }^{31}$. Other studies have shown that UK professionals do not give information to women about the risks of obesity and the importance of weight management before or during pregnancy ${ }^{13}$.

According to the guidance from the National Institute for Health and Care Excellence issued in 2010, all health professionals involved in antenatal and postnatal services should engage women in dietary and physical activity interventions for weight management before pregnancy ${ }^{6}$. These interventions should include advice on dietary and behaviour change in order to maintain a healthy weight and also effective weight loss programmes by encouraging regular physical activity ${ }^{6}$. During pregnancy, dieting is not recommended and women should have around 200 calories more a day in the last trimester of pregnancy 6 . Also, moderateintensity physical activity will not harm the woman or her unborn child and is generally advised ${ }^{6}$.

There is currently no national guidance for UK professionals for weight management after childbirth. It has been suggested that managing a woman's weight in the first few years after childbirth may reduce her risk of entering the next pregnancy overweight or obese ${ }^{6}$. Strategies that have been proposed involve having a healthy diet, taking a regular exercise and exclusive breastfeeding. The additional energy requirements of breastfeeding may help women return to their prepregnancy weight ${ }^{32}$. Moreover, if women are moderately active on a regular basis, this will not adversely affect their ability to breastfeed and could aid weight management ${ }^{6}$.

\section{Limitations and strengths}

There are certain limitations to be considered in this study. First, this was a retrospective cohort study with the data being collected from an electronic database. This means that the accuracy of the final data was dependent on the practitioner entering each time the information on the database at the time of delivery. Second, we were unable to retrieve data about the induction of the labour process and the medications used, as this information is not recorded on the database and would therefore require manually retrieving the hospital notes for all women of the cohort, which logistically would be impossible. Third, the weight gain during pregnancy is not a mandatory field in the obstetric database that was used and therefore this information was missing.

The main strength of our study was that it included a large sample of women that generated statistically significant results comparable to those referenced in the literature for other countries. Moreover, the large sample size included women who were primigravidae, under 40 years old, whiteEuropean ethnic background, and without epidural use during labour, in order to account for the significant confounding factors of parity, maternal age, ethnicity and labour analgesia on the success of induced labour ${ }^{3,18-20}$.

\section{CONCLUSIONS}

We have found that an increasing BMI in women with induced labour was associated with increased caesarean-section rates and lower Apgar scores. These findings highlight the important role of midwives as frontline health professionals in weight management before pregnancy.

\section{REFERENGES:}

1. World Health Organization: "WHO global database on body mass index". http://apps.who.int/bmi/index.jsp. Accessed October 2017.

2. Masho SW, Bishop DL, Munn M. Pre-pregnancy BMI and weight gain: where is the tipping point for preterm birth? BMC Pregnancy Childbirth. 2013;13(120). doi: 10.1186/1471-2393-13-120

3. Papoutsis D, Antonakou A, Gornall A, Tzavara C, Mohajer M. The $\mathrm{SaTH}$ risk-assessment tool for the prediction of emergency cesarean section in women having induction of labor for all indications: a large-cohort based study. Arch Gynecol Obstet. 2017;295:59-66. doi: 10.1007/s00404-016-4209-4

4. Health survey for England 2006: CVD and risk factors adults, obesity and risk factors children. London: The NHS Information Centre, 2008.

5. Heslehurst N, Rankin J, Wilkinson JR, Summerbell CD. A nationally representative study of maternal obesity in England, UK: trends in incidence and demographic inequalities in 619323 births, 1989-2007. Int J Obes (Lond). 2010;34(3):420-8. doi:10.1038/ijo.2009.250

6. National Institute for Health and Care Excellence (NICE). Weight management before, during and eight management before, during and after pregnancy after pregnancy. Public health guideline. https://www.nice.org.uk/guidance/ ph27 Published: July 2010. Accesed October, 2017.

7. Villamor E, Cnattingius S. Interpregnancy weight change and risk of adverse pregnancy outcomes: a populationbased study. Lancet. 2006;368(9542):1164-70. doi:10.1016/s0140-6736(06)69473-7

8. Yu CK, Teoh TG, Robinson S. Obesity in pregnancy. BJOG. 2006;113(10):1117-25. doi: 10.1111/j.1471-0528.2006.00991.x

9. Bhattacharya S, Campbell DM, Liston WA, Bhattacharya S. Effect of Body Mass Index on pregnancy outcomes in nulliparous women delivering singleton babies. BMC Public Health. 2007;7(1):168. doi:10.1186/1471-2458-7-168

10. Mclntyre HD, Gibbons KS, Flenady VJ, Callaway LK. Overweight and obesity in Australian mothers: epidemic or endemic? Med J Aust. 2012;196(3):184-88. doi: 10.5694/mja11.11120

11. Sebire NJ, Jolly M, Harris JP, Wadsworth J, Joffe M, Beard RW, et al. Maternal obesity and pregnancy outcome: a study of 287,213 pregnancies in London. Int J Obes Relat Metab Disord. 2001;25(8):1175-82. doi:10.1038/sj.ijo.0801670

12. Ramachenderan J, Bradford J, McLean M. Maternal obesity and pregnancy complications: a review. 
Aust N Z J Obstet Gynaecol. 2008;48(3):228-35. doi:10.1111/j.1479-828X.2008.00860.x

13. Heslehurst N, Lang R, Rankin J, Wilkinson JR, Summerbell CD. Obesity in pregnancy: a study of the impact of maternal obesityonNHSmaternityservices.BJOG.2007;114(3):33442. doi:10.1111/j.1471-0528.2006.01230.x

14. The NHS Maternity Statistics, England:2013-14: The Health and Social Care Information Centre. http://www.hscic.gov. uk/catalogue/PUB16725. Accesed October 2017.

15. Talaulikar VS, Arulkumaran S. Failed induction of labor: strategies to improve the success rates. Obstet Gynecol Surv. 2011;66(11):717-28. doi:10.1097/OGX.Ob013e31823eOc69

16. Zhang J, Troendle J, Reddy UM, Laughon SK, Branch DW, Burkman R, et al; Consortium on Safe Labor. Contemporary cesarean delivery practice in the United States. Am J Obstet Gynecol. 2010;203:(4)326.e1326.e10. doi: 10.1016/j.ajog.2010.06.058

17. National Institute for Health and Care Excellence (NICE). Induction of labour. National Collaborating Centre for Women's and Children's Health. RCOG Press, London. https://www.nice.org.uk/guidance/cg70. Published July 2008. Accessed October 2017.

18. Smith GC, Cordeaux Y, White IR, Pasupathy D, Missfelder-Lobos H, Pell JP, et al. The effect of delaying childbirth on primary cesarean section rates. PLoS Med. 2008;5(7):e144. doi:10.1371/journal.pmed.0050144

19. Antonakou A, Papoutsis D. The Effect of Epidural Analgesia on the Delivery Outcome of Induced Labour: A Retrospective Case Series. Obstet Gynecol Int. 2016;(2016):5740534. doi: 10.1155/2016/5740534

20. Papoutsis D, Antonakou A, Tzavara C. The Effect of Ethnic Variation on the Success of Induced Labour in Nulliparous Women with Postdates Pregnancies. Scientifica (Cairo). 2016;(2016):9569725. doi:10.1155/2016/9569725

21. Torricelli M, Voltolini C, Conti N, Bocchi C, Severi FM, Petraglia F. Weight gain regardless of prepregnancy BMI and influence of fetal gender in response to labour induction in postdate pregnancy. J Matern Fetal Neonatal Med. 2013;26(10):1016-19. doi: 10.3109/14767058.2013.766712

22. Baranova A, Gowder SJ, Schlauch K, Elariny H, Collantes R, Afendy A et al. Gene expression of leptin, resistin, and adiponectin in the white adipose tissue of obese patients with non-alcoholic fatty liver disease and insulin resistance. Obes Surg. 2006;16(9):1118-25. doi:10.1381/096089206778392149

23. Melzer K, Schutz Y, Soehnchen N, Othenin-Girard $\mathrm{V}$, Martinez de Tejada B, Irion $\mathrm{O}$, et al. Effects of recommended levels of physical activity on pregnancy outcomes. Am J Obstet Gynecol. 2010 Mar;202(3):266. e1-6. doi: 10.1016/j.ajog.2009.10.876

24. Domenjoz I, Kayser B, Boulvain M. Effect of physical activity during pregnancy on mode of delivery. Am J Obstet Gynecol. 2014 Oct;211(4):401.e1-11. doi: 10.1016/j.ajog.2014.03.030

25. Antonakou A, Papoutsis D. The Effect of Fetal Gender on the Delivery Outcome in Primigravidae Women with
Induced Labours for all Indications. J Clin Diagn Res. 2016;10:22-25. doi:10.7860/jcdr/2016/22099.9104

26. Viegas OA, Lee PS, Lim KJ, Ravichandran J. Male fetuses are associated with increased risk for cesarean delivery in Malaysian nulliparae. Medscape J Med.2008;10(12):276.

27. Lee KA, Mi Lee S, Jin Yang H, Park CW, Mazaki-Tovi S, Hyun Yoon B, et al. The frequency of meconium-stained amniotic fluid increases as a function of the duration of labor. J Matern Fetal Neonatal Med 2011;24:880-5. doi:10.3109/14767058.2010.531329.

28. Becker S, Solomayer E, Dogan C, Wallwiener D, Fehm T. Meconium-stainedamnioticfluid--perinataloutcomeand obstetricalmanagementinalow-risksuburbanpopulation. Eur J Obstet Gynecol Reprod Biol. 2007;132(1):46-50. doi:10.1016/j.ejogrb.2006.05.032

29. Institute of Medicine and National Research Council: "Weight gain during pregnancy: re-examining the guidelines". Washington, DC: National Academies Press, 2009.

30. Institute of Medicine and National Research Council: "Leveraging Action to Support Dissemination of Pregnancy Weight Gain Guidelines - Workshop Summary". September 2013.

31. Foster C, Hirst J. Midwives' attitudes towards giving weight-related advice to obese pregnant women. Br J Midwifery. 2014:22(2);254-62. doi: https://doi.org/10.12968/bjom.2014.22.4.254

32. Antonakou A, Papoutsis D, Kechagia A. Does gestational weight gain of more than $12 \mathrm{~kg}$ in women increase the risk of a cesarean section delivery, gestational diabetes and pregnancy induced hypertension? A retrospective case series. Clin Exp Obstet Gynecol. 2017:4;540-545.

\section{ACKNOWLEDGEMENTS}

We would like to thank Chris Weston, data analyst of Medway electronic database at the Shrewsbury and Telford Hospital NHS Trust for his contribution and support in the data collection for this study.

CONFLICTS OF INTEREST

Authors have completed and submitted the ICMJE Form for Disclosure of Potential Conflicts of Interest and none was reported.

\section{FUNDING}

There was no source of funding for this research.

PROVENANGE AND PEER REVIEW

Not commissioned; externally peer reviewed 